\title{
Language Contact in Colombia: A Pilot Study of Criollo Sanandresano ${ }^{1}$
}

\author{
Margarita María Chamorro Díaz \& Cristina Suárez-Gómez ${ }^{\dagger}$
}

The present linguistic situation of Colombia counts with more than 68 indigenous languages from different languages families. These indigenous languages are mostly spoken in bordering regions of the country, as well as in settlements located in diverse ecological regions. One of these indigenous languages is the Criollo Sanandresano (SAC) spoken in the islands of San Andrés, Providencia and Santa Catalina, located on the north-west Atlantic coast of Colombia, with the status of official language since 1991 (Article 10, Constitution of Colombia). Criollo Sanandresano, the vehicular language here in informal conversations, is an English-based creole that developed in the seventeenth century and emerged after a process of language contact with English (superstrate), West African languages (from the Atlantic slave trade) and Spanish (substrate languages). Following Thomason (2001: 63), we assume that in situations of language contact all language levels can be affected and "anything" can be adopted from the languages in contact. Our aim in this paper is to describe the current situation of Criollo Sanandresano and to analyze it from a linguistic point of view, in order to see whether the acknowledged view that creoles have a simpler grammar (e.g. lack of inflectional morphological markers, development of analytical particles, etc.) and more internal variability than older, more established languages holds (McWhorter 2005, Thomason 2001). This analysis will be based on a selection of texts available at the Instituto Caro y Cuervo and it will pay special attention to a selection of morphosyntactic variables in the light of contact linguistics and creolization processes.

Keywords: Caribbean creoles, Language contact, Language attitudes, Morphosyntactic variation, Spoken language

\section{Introduction}

The present linguistic situation of Colombia counts with more than 68 indigenous languages from different languages families, 2 creole languages, Romaní and Spanish, divided into two main varieties: Español Costeño (regions of the Pacific and Atlantic coasts) and Español Andino (rest of the country). These indigenous languages are mostly spoken in bordering regions of the country, as well as in settlements located in diverse ecological regions. One of these indigenous languages is the Criollo Sanandresano (henceforth SAC) spoken in the islands of San Andrés, Providencia and Santa Catalina, located on the north-west Atlantic coast of Colombia. Together with Spanish, SAC has been the official language of these territories since 1991 (Article 10, Constitution of Colombia). The dominant language spoken here nowadays is Spanish, spoken by $98 \%$ of the population, irrespective of context and age (Andrade Arbeláez 2012), although SAC remains the vehicular language in informal conversations.

\footnotetext{
*Centro Educativo y Cultural Español Reyes Católicos, Spanish Embassy in Colombia, Colombia. ${ }^{\dagger}$ Senior Lecturer, University of the Balearic Islands, Spain.

${ }^{1}$ For support with this study, our gratitude goes the Spanish Ministry of Science and Innovation and the European Regional Development Fund (Grants No. FFI2014-53930-P and FFI 201782162-P) and the Instituto Caro y Cuervo (Ministry of Culture, Colombia).
} 
SAC is an English-based creole that developed in these islands in the seventeenth century and emerged after a process of language contact with English (superstrate), West African languages (from the Atlantic slave trade) and Spanish (substrate languages). Following Thomason (2001: 63, Bolton 2006) we assume that in situations of language contact all language levels can be affected and "anything" can be adopted from the languages in contact, vocabulary, phonological or structural features.

Our aim in this paper is to describe the current situation of Criollo Sanandresano and to analyze it from a linguistic point of view, in order to see whether the acknowledged view that creoles have a simpler grammar (e.g. lack of inflectional morphological markers, development of analytical particles, etc.) and more internal variability than older, more established languages holds (McWhorter 2005, Thomason 2001). The analysis will be based on a selection of texts available at the Instituto Caro y Cuervo and it will pay special attention to morphosyntactic variables in the light of contact linguistics and creolization processes, in particular, to the pronominal system, the pluralization of nouns, and to the system of clausal negation, all of them features frequently analyzed in English-based creoles.

The paper is structured as follows. Next sections give an overview of creolization and language contact processes and the history and current status of SAC is provided. Following, we describe the corpus used for the analysis and the analysis itself is presented and discussed. Finally, we provide a summary of the main conclusions.

\section{Creolization and Language Contact}

The term 'creole' is frequently used in combination with 'pidgin'. Both terms make reference to linguistic systems and the most important difference between both is the absence of native speakers in "pidgin" languages as opposed to their existence in creoles. A creole has been defined as "a language that has come into existence at a point in time that can be established fairly precisely" (Muysken \& Smiths 1995: 3), and as a language that develops in "contact situations that typically involve more than two languages" (Thomason 2001: 159). Creoles developed for purposes of communication (e.g. context of slavery and/or trade) between groups of people from different linguistic backgrounds (Thomason 2001: 158) and very often also different social backgrounds. Creoles are languages that emerge out of a specific type of language contact. According to Thomason (2001: 60), creoles, together with pidgins and bilingual mixed languages, are classified as a case of "extreme language mixture" in the classification of language contact typologies: there is lexifier-or superstrate, very often the language of the powerful groups (commonly English, Spanish or Portuguese) and the substrate(s), the languages of the indigenous population (in cases of colonization) and also of the less powerful groups (slaves, labourers, etc.). 
Research on specific creoles discovered the existence of different varieties within the same creole, which gave place to what is known as the creole continuum (DeCamp 1977). It makes reference to the different varieties which can be distinguished within a creole and are classified in terms of their degree of closeness to the lexifier language. The emergence of these varieties is justified by the coexistence of the creole with its lexical source language. In such context, "there is a social motivation for the creole speaker to acquire the standard, so that the speech of individuals takes on features of the latter -and avoid features of the former- to varying degrees" (Holm 1988: 52, Winford 1993: 7-8). At one end of the continuum, there is the acrolect, the closest one to the standard and therefore the most prestigious variety, "generally used by the society's elite: the well-educated, well-off professionals" (Singh 2000: 74); at the opposite end, the basilect, the least prestigious variety, "the variety that is most creole-like, typically spoken by those who are at the bottom of the socioeconomic ladder and so have the least access to institutions such as education and therefore to the standard" (Singh 2000: 74). In between, we find the mesolect, with speakers "more or less creole- or standard-like, depending on their individual access to, and identification with, the basilect or acrolect", and combine features from both the creole and the standard (Singh 2000: 75). The selection of one of these varieties is determined by social prestige (normally it is the language of education, administration, religion, etc.), education, age, and also factors such as degree of formality. But not all speakers are affected by this 'corrective pressure' of adopting the standard and the continuum emerges according to a certain degree of acculturation, which "varies with such factors as age, poverty, and isolation from urban centres" (DeCamp 1971: 351).

The earliest theories dealing with the genesis of creoles were Eurocentric and gave emphasis to the superstrate language. Since pidgins and creoles were initially developed for purely functional purposes-as a mean of communication between peoples with different native languages unintelligible between themselves, creoles have traditionally been considered "maximally simple" linguistic systems, and "all alike" (Thomason 2001: 159, Mühlhäusler 1986: 135, Muysken \& Smith 1995: 8-9, Singh 2000: 2, Thomason 2001: 167-174, Le Page 1977: 231). In fact, very often pidgins and creoles are described as 'broken' languages without structure or grammatical rules, mainly because they are conceived as simplified versions of their lexifier languages. This is the view adopted by the so-called 'Foreign Talk Theory', according to which language use is adapted when the speaker is speaking to a non-native speaker, with strategies of simplification and imitation dominating. Another theory is the 'Imperfect L2 Learning Hypothesis', which resorts to mechanisms of acquiring the superstratal target. This simplistic views, which took the language of the lexifier as the target (superstratal target hypothesis), considered creoles as the products of 'imperfect learning' and deviations from the model; they have been pejoratively described as "bastardized versions of the lexifier language" and the 'language of the slaves', because "most speakers of most 
creoles are descendants from slaves, so the languages are seen as fit only for slaves" (Thomason 2001: 189).

Regarding the "they are all alike" characterization, this relies on the perceived similarities between creoles, especially at the level of phonology (e.g. lack of 'exotic' sounds and complex consonant clusters), morphology (e.g. lack of inflectional and derivational morphology), lexis (e.g. reduced stock of lexical vocabulary) or syntax (e.g. SVO word order or particular distribution of particles indicating TAM, more coordination than subordination, etc.). Most of these features shared by creoles are not necessarily poorer versions of the lexifier's grammar, but rather universal features observed in language acquisition processes (cf. 'vernacular universals' of non-standard varieties of English, Chambers (2004)). Furthermore, detailed studies of creoles demonstrate that creoles with different lexifiers (e.g. English-based creoles vs French-based creoles) are not so "all alike", as opposed to creoles which share a lexifier, which also share more features. Although historically they were viewed with contempt, they have become relevant objects of study for language evolution, official languages (language planning and educational policies), and languages their speakers are proud of. In fact, once a creole develops, it becomes the linguistic variety of a speech community, with native speakers (L1 of a community), used not only for purposes of communication between the groups of unintelligible languages, but also between members of the community (expansion phase), which identify themselves with this emerging variety (Le Page \& Tabouret-Keller 1985). It is a language which acts as a marker of peergroup identity and of alienation from the dominant. It is at this moment when the creoles develop their own phonological, lexical, morphosyntatic, pragmatic and stylistic rules, in what has been labelled a creolization process.

Alternative views to the 'superstrate target' put emphasis on the substrate languages. Within these theories, the most popular one is the theory of the monogenesis, which states that all pidgins and creoles are ultimately descendants of a proto-pidgin formed on the West African coast (defended by Lefebvre 1993, 1998). This hypothesis would also justify the 'they are all alike' claim pointed before, especially in what refers to grammar and sounds. Following this hypothesis, all English-lexicon Caribbean creoles would be direct descendants of a pidgin that emerged on the coast of West Africa (Thomason 2001: 177). The differences among creoles are justified by 'relexification' (Thomason 2001: 176; Stewart 1962: 42). This gave place to the so-called 'Relexification Hypothesis', defended by Lefebvre (1993, 1998), according to which "creoles are created by adults who develop a new lexicon by combining the phonetic shapes of one language with the semantic and syntactic information of another language" (Thomason 2001: 179). Borrowing is a key process in this hypothesis and no process of negotiation between languages is contemplated (Thomason 2001: 180). For the Caribbean, Hancock (1986) proposed Guinea Coast Creole English as the proto-language from which relexification in the New World took place. For the superstratists, however, the similarities between creoles are "because they developed in 
similar environments in similar circumstances, with dialectal forms of on superstratal language, English" (Singh 2000: 49).

Other hypotheses establish a parallelism between the genesis of creoles and processes of language acquisition. Here, the Language Bioprogram Hypothesis (LBH) proposed by Bickerton (1981, 1988 and references therein) is of special relevance. He compares the process of creolization with processes of L1 acquisition. Following this hypothesis, the grammar of a creole is developed in every infants' brain who are genetically programmed for such development (universal innate features, UG, or the language bioprogram). Creoles emerge in new contact situations where a new language is necessary for all communicative purposes and follow a three-step process: from macaronic prepidgin to unstable prepidgin which derives into the crystallization of a new creole's grammar in the one or even two subsequent generations (see Thomason 2001: 178 for a summary). This hypothesis would account for the shared features of creoles (and other vernacular linguistic systems), such as the widely referred TMA system. The most important criticism to the LBH is that it does not contemplate the social and historical background of creoles formation.

Thomason (2001), among others, also compares the genesis of creoles with a language acquisition processes, but she puts more emphasis in L2s (SLA hypothesis). In her opinion, creoles follow a learning process comparable to the acquisition of L2s "in which the people in the new contact situation learn to communicate with each other by deploying the new vocabulary with grammatical structures they hope will be understood by their interlocutors" (2001: 180). This process entails negotiation between the native languages and the lexifier language and therefore shift-induced interference; the resulting creole grammar "is a crosslanguage compromise among the languages of the pidgin/creole creators" (2001: 181). Following this hypothesis, shared features among creoles are accounted as universally unmarked features associated to learning processes and/or derivable from the native language(s).

Other hypothesis for the genesis of creoles resort to less abrupt contactlanguage genesis scenarios. The main tenet is that the development of creoles is progressive and the source is either (i) as fully crystallized pidgins (i.e. 'pidgin-turned-creoles') (Thomason 2001: 183; see also Chaudenson 1992) or (ii) as evolved creoles from those founded into small colony settings to largescale plantations where ultimately the slave population rapidly outnumbered their masters (mostly based on demographic evidence) (Thomason 2001: 184, 188, Singler 1996). The gradualist view is defended by Chaudenson (1992), who accounts for French-lexifier creoles in the Indian Ocean as extensively modified French varieties, from the different waves of slaves arriving subsequently. These varieties would follow an ordinary L2 acquisition process, with ordinary contact-induced change, happening repeatedly up to the extent that the emergent varieties cannot longer be considered varieties of French. According to Singler (1996), the genesis of creoles in the Caribbean has to be found in the original sugar colonies present in these lands before the sugar boom, which had a demographic impact. 


\section{Criollo Sanandresano (SAC)}

The present linguistic situation of Colombia counts with more than 68 indigenous languages from different languages families, 2 creole languages, Romaní and Spanish, the latter divided into two main varieties: Español Costeño, spoken in the regions of the Pacific and Atlantic coasts, and Español Andino, spoken in the rest of the country. The two creole languages are Palenquero, a Spanish-based creole, spoken in San Basilio de Palenque, and Criollo Sanandresano (SAC), an English-based creole, spoken in the archipelago of San Andrés, Providencia and Santa Catalina.

SAC developed in the seventeenth century as a consequence of the British colonization, which brought slaves to the Caribbean from Africa who spoke typologically different languages (Patiño-Roselli 2002). It emerged after a process of language contact with English, the superstrate, and West African languages (from the Atlantic slave trade) and Spanish, as the substrate languages. As most creoles, SAC emerged for purposes of communication between peoples from different linguistic backgrounds (Thomason 2001: 158).

Linguistically speaking, the islands of San Andrés, Providencia y Santa Catalina, have a trilingual situation nowadays. SAC coexists with Spanish and English. In San Andrés, SAC is an official language since 1991. It is the native language of the local ethnic group known as raizal, who arrived in the seventeenth century to these islands from the migrations coming from Jamaica. Spanish, also an official language, is the dominant language in these territories, especially since the declaration of San Andrés as free port in 1953, which brought many Spanish-speaking Colombian people. As a consequence, the raizal community became a demographic and linguistic minority in San Andrés (Sanmiguel 2007). SAC is also an official language in the islands of Providencia and Santa Catalina, but here, unlike in San Andrés, it is also the dominant language. As to Standard English, it is daily used, but confined to religious services (Abouchaar et al. 2002).

The distribution of the available languages is mostly diglossic (MoyaChaves 2010), as is often the case in communities where languages with different prestige coexist. Spanish is the language used by the government, in education and in the media, while SAC is the home language, selected in informal conversations. Although $79.5 \%$ of the raizal population speak SAC, there is an increasing use of Spanish as the only language, also derived from the touristic activity (Sanmiguel 2007, Moya-Chaves 2010). As to English, it is mostly kept in religious services, and is considered a prestigious language by the local population.

In education, the favoured language is Spanish. There have been attempts from the government to promote SAC, however these are restricted to primary school and only as a spoken language mainly to explain and clarify concepts (Abouchaar et al. 2002). In fact, in the last few years English has been given more importance at school and all proposals of a bilingual education include English and Spanish and leave SAC aside (Abouchaar et al. 2002, MoyaChaves 2010). Generally, all the programs focus on promoting English, which 
is usually associated with professional success. The only proposal which took into account SAC as a language of education was the trilingual project led by the Universidad Cristiana de San Andrés (Morren 2001, Bowie \& Dittman 2007, Guerrero 2008), whose aim was to implement a trilingual educational curriculum, which included SAC in students between 6 to 10 years, English from 7 years onwards, Spanish from 8 years onwards, and having 50\% Spanish and $50 \%$ English from the age of 11 onwards. This program was not successful mainly due to the lack of funding and support from the local authorities, as observed by Bowie and Dittman (2007: 72).

Regarding the promotion of SAC, it is important to highlight the efforts made by the Instituto Caro y Cuervo, an official institution depending on the Ministry of Culture which fosters research on linguistics, literature and philology of Spanish and the local languages of Colombia ${ }^{2}$.

Not many studies exist on SAC, with the exception of the descriptive studies carried out by Dittman (1992) and O'Flynn de Chaves (2002). In terms of vocabulary, it is basically derived from English, the lexifier, as usually happens with creoles (Thomason 2001: 160). Regarding the phonological system (Dittman 1992: chapter 2), SAC distinguishes from seven vowels in the basilect to twelve vocalic sounds in the more acrolectal variety, as also found in other Caribbean creoles. Morphosyntactically SAC is very similar to other Caribbean English-based creoles. Among the most relevant features reported by Dittman (1992), SAC resorts to the unmarked SVO clausal word-order, topicalization of structures for emphasis, the use of particles for TAM (e.g. de and wen de for the progressive or go and gwain for the future), lack of inflectional endings, as for instance to indicate the present-past tense distinction of lexical verbs, copula deletion in the present tense or the use of invariable negators no or never preceding the lexical verb.

\section{Corpus and Methodology}

The data under analysis here come from a local project coordinated by Marcia Dittman and supported by the Instituto Caro y Cuervo to keep the local traditions alive. The data include the speech of three local women narrating their own lives, memories from their childhood, local stories and local traditions. Therefore, these texts represent spoken spontaneous language, the medium generally considered the most vernacular type of language.

A total of almost 5,000 words were included and the retrieval of examples proceeded in two steps. In order to ensure a maximally exhaustive search, we first retrieved examples automatically of the different variables under analysis using AntConc. Next these examples were analyzed manually in order to select the relevant examples and to discard invalid instances from the database. The manual analysis was also necessary in order to retrieve instances which

\footnotetext{
${ }^{2}$ Portal de Lenguas de Colombia. Diversidad y contacto. Instituto Caro y Cuervo. http://lenguasde colombia.caroycuervo.gov.co/ (Accessed on 2017-11-30).
} 
were not possible to extract automatically. This entailed the careful reading of the texts.

There are a few limitations of this study. For instance, the material that is investigated is not as extensive as was wished since it comes from only three female speakers who deal with a limited range of topics. We cannot discard that the tendencies that have been found in the analysis only exist in the sample from the texts used in this study.

The informants are three local women, permanent residents of San Andrés, who received a limited amount of education. They are strongly identified with the raizal community, that is, the community they represent. They are considered mesolectal speakers of SAC.

Despite these limitations, we carried out an analysis of a selection of morphosyntactic variables usually analyzed in Caribbean English-based creoles: (i) the pronominal system; (ii) nominal morphology, in particular the expression of plural in nouns; and (iii) the system of clausal negation.

\section{Analysis}

This section contains a preliminary description of SAC, relying primarily on the analysis of the texts described in the section of corpus and methodology. This description is based on the analysis of clausal units in isolation, which has been found to be necessary in identifying variants within morpho-syntactic variables (Givón 1984: 10), although sometimes reliance on discourse is necessary to determine certain meanings.

As summarized before SAC has been described in some studies (Dittmann 1992, O'Flynn the Chaves 2002), mostly from a qualitative point of view. Although quantitative analyses cannot be thorough due to the limited number of data, our aim is to complete previous descriptions and studies, and provide some quantitative data which will help us get a finer picture of morphosyntax in SAC. Additionally, our intention is not simply to analyze SAC as a single creole, but also to compare SAC with other related creoles, in particular other Caribbean creoles such as Jamaican Creole and Trinidadian and Tobago Creole, and place it within the linguistic map of creoles.

This analysis has been carried out following a variationist approach, whereby linguistic variation is conceived to be orderly and shows "structured heterogeneity" (Labov 1972). Thus, we selected a number of linguistic variables which fulfilled the following requisites: (i) variables of relevance and repeatedly studied in creoles; (ii) variables which were included in previous studies of SAC, in order to allow comparison; and (iii) relatively frequent variables to facilitate not only a qualitative analysis but also a quantitative one in the reduced sample we are working with. 


\section{Pronominal System}

SAC pronominal system has been briefly described by Dittmann (1992) and O'Flynn de Chaves (2002). The latter mentions a pronominal system variable in terms of person and number (also animacy in the third person), but invariable in terms of case (2002: 21), as opposed to Dittmann, who mentions in passing the use of alternative forms.

In order to ensure a maximally exhaustive search, we first carried out a manual analysis which entailed the careful reading of the texts. Then, we retrieved examples automatically using AntConc of the different forms found in the manual analysis. A careful analysis of the corpus shows the pronominal system of Table 1 (only forms which appear at least four times have been included in the table).

Table 1. Distribution of Pronominal Forms

\begin{tabular}{|c|c|c|}
\hline & Singular & Plural \\
\hline \multirow{3}{*}{ First person } & Subject: $a i$ & \multirow[t]{3}{*}{ Subject and object: $\underline{w i}^{3}$} \\
\hline & Object: $\underline{\overline{\boldsymbol{m i}}}$ & \\
\hline & Possessive determiner: $\mathrm{mai}^{4}$ & \\
\hline \multirow{2}{*}{ Second person } & $\begin{array}{l}\text { Subject and determiner: } y u \text {, } \\
\boldsymbol{y o}^{5}\end{array}$ & \multirow[t]{2}{*}{ Not found in the corpus } \\
\hline & Object: $y u$ & \\
\hline \multirow{3}{*}{ Third person } & Subject: shi, $h i(m)^{6}$ & \multirow{3}{*}{$\begin{array}{l}\text { Subject: } \frac{d e m}{d e m}, \underline{d e i} \\
\text { Object: }\end{array}$} \\
\hline & Object: har, him & \\
\hline & Subject and object: it, ih & \\
\hline
\end{tabular}

Note: *those in boldface were found by O'Flynn de Chaves (2002); those underlined are variants listed by Dittman (1992).

Table 1 shows that personal pronouns in SAC may vary according to person, number, case and, in the third person singular, also gender and animacy, although syncretism occurs very often, as O'Flynn de Chaves points out. In fact, the pronominal system reflects in general terms what has been previously shown by O'Flynn de Chaves (2002: 21), although it brings to light pronominal forms that had not been previously mentioned. Both the forms and the system seem to be ultimately derived from English, unlike other creoles, such as Tok Pisin, where the pronominal morphemes are derived from English, but the system lacks the English gender and case distinction characteristic of English (Thomason 2001: 171), or Trinidadian Creole (Deuber 2014: 107-108), which shows invariable forms for case and gender in the basilect, but introduces alternative forms in the mesolect.

For the first person plural, wi is the form invariably used for the plural, irrespective of the syntactic function it plays (cf. Present-day English we-us), as opposed to the singular, where we find the availability of more forms, very

\footnotetext{
${ }^{3}$ One occurrence of the form we has been also found functioning as DO.

${ }^{4}$ The form $m i$ has also been recorded once in the corpus.

${ }^{5}$ The form you as a subject form occurs in one occasion.

${ }^{6}$ The form $\mathrm{im}$ for the nominative has been also found once.
} 
frequently distributed according to case: $a i$, invariably nominative, $m i$, invariably object, and mai, possessive determiner. For the second person, no form for the plural has been found in our corpus, although unu is the form mentioned by O'Flynn de Chaves (2002). For the singular, yu and yo are indistinctively used as subject and object (cf. Present-day English you). Finally, regarding the third person, dem and dei coexist for the plural; both forms are used as subject and as object, all the examples found resort to dem. As to the singular, different forms are used for the distinction non-human vs human. If the referent is human, there is a gender distinction: shi (nominative) and har (object) for human feminine referents and him (both as subject and object) and hi (nominative) for masculine referents. With non-human referents, the forms it and ih are selected. Example (1) shows a distribution conditioned by case: it used as subject, and $i h$, as object:

(1) It foum wen yu put ih, it foum ("It foams when you put it, it foams...")

However, this conditioned distribution does not hold in all the examples of the corpus, as examples (2) illustrates:

(2)Yu jos rob ih an di skin an ih born. Bot ih hiil ih quik, it hiil it ("You just rub it on the skin and it burns. But it heals it quick, it heals it")

In example (2) case can no longer be used to justify the distribution of it and $i h$, as they are both indisctinctively used as subject and object. A tentative hypothesis to justify their use is for emphasis (see the repetition of "it heals it") and also in compliance with the horror aequi principle (Rohdenburg 1996), which refers to the avoidance of formally (near-) identical adjacent elements.

\section{Noun Morphology}

Figure 1. Distribution of Plural Markers

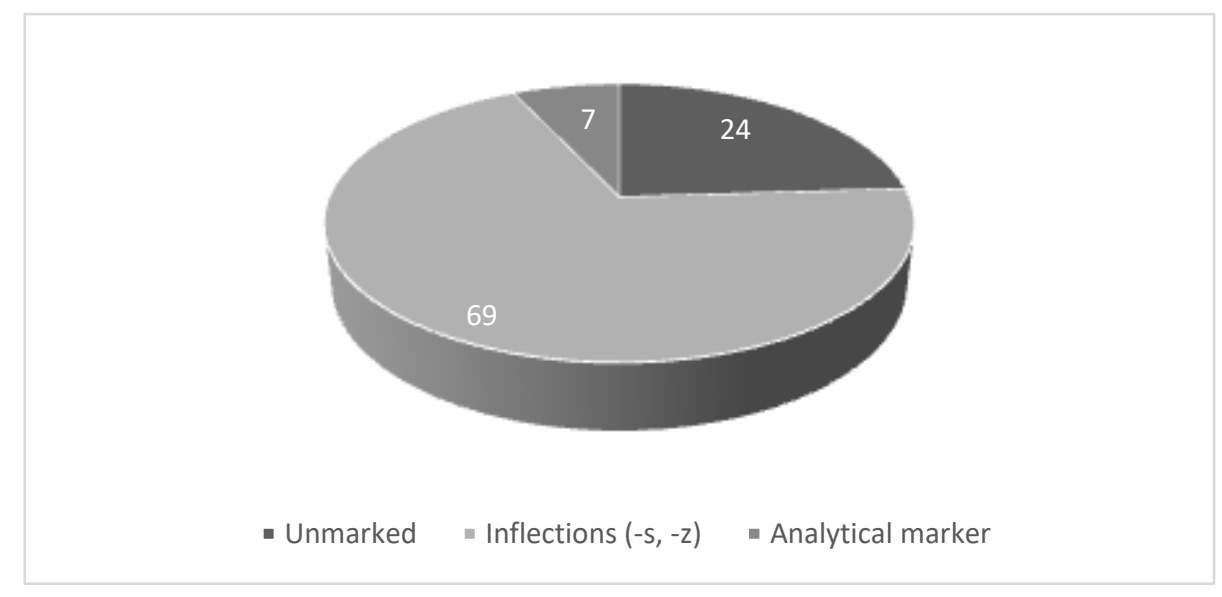

Nouns in SAC show a binary system in terms of number, which distinguished singular from plural nouns. As in Present-day English, singular 
nouns are unmarked. As to plural nouns, a three-fold distinction was found in the corpus under analysis, as shown in Figure 1.

Figure 1 shows that the most frequent way of pluralizing nouns in SAC is by adding the inflectional plural marker-s/-z (e.g. deiz 'days', fruuts 'fruits', tingz 'things', (gran)pierenz/pierns 'grandparents, parents', etc.); however this coexists with unmarked plural nouns $(24 \%)$, that is, nouns used in the plural which do not add any marker, with a higher frequency than what has been reported by Deuber for other Caribbean creoles such as Jamaican Creole (2014: 107) or Trinidadian Creole (2014: 162). This is illustrated in examples (3) and (4):

(3)In di fortiØ ("In the forties")

(4)Dei kil aut al di monkiØ waz in di haus ("They killed all the monkeys who where in the house")

(5)Fig trii liifØ dat gud. Yu kyan get liifØ an bail dem in waata, two ar three liif $\emptyset$ ("Fig tree leaves are good. You can get leaves and boil them in water, two or three leaves")

Although inflectionally unmarked, and therefore formally similar to the singular, the context clearly avoids any possibility of confusion, as al ('all'), two, three in the examples above indicate plurality. Since in these examples there are other contextual markers of plurality, a tentative hypothesis to justify the availability of unmarked plural nouns is to favour isomorphism, a tendency in language to reflect a one-to-one correlation between form and meaning, and thus aim at maximizing transparency (see Leufkens (2015) for a thorough analysis of transparency in language).

Finally, pluralization of nouns in SAC is also expressed by analytical means, namely by placing the pronominal form dem postnominally, as in examples (6), (7) and (8):

(6)Di paña dem sei "sana" ("Spanish people (they) say 'healthy"')

(7)Di man dem drink it ("The men (they) drink it")

(8)Yu bail di liif dem in waata an drink ih ("You boil the leaves in water and drink it")

Examples (6) and (7) can also be argued as cases of left-dislocation to topicalize selected elements; however, this interpretation is not possible in example (8), where dem unambiguously acts as a plural marker.

\section{Clausal Negation}

In creoles, preverbal negators are frequently used, and SAC is not an exception in this respect; this is also cross-linguistically supported (Dryer 1988). O'Flynn de Chaves (2002: 21) include preverbal no and neva as the sentential negators of SAC. To these two, Dittman (1992: 71-72) adds don and $\operatorname{din}(t)$. Examples (9)-(12) illustrate these four possibilities: 
(9) An hel wen yu hav yur period, hel yu dat yu no have pein ("And it helps when you have your period, it helps that you don't have pain")

(10) Wi neva nou wich piis a di klat waz di dress ("We didn't know which piece of cloth was the dress")

(11) Shid sit daun with wi an shi didn haid wat shi now laik some pierenz ("She would sit down with us and she didn't hide what she knew, like some parents (did)")

(12) Wen ai waz in San Andres, ai hav al mai children daun der. Afta ai don hav mai children, ai ritorn bak hir ("When I was in San Andrés, I had all my children there. After I haven't had more children, I returned back here")

In the analysis of our corpus, we observed that the negators previously mentioned are also selected in our set of data, but they are not randomly used. Rather, they are distributed in terms of tense. For the present tense no and nou are the default makers (example (9)), with isolated cases of don. As to the past tense, there is more variation, and neva, didn and don coexist (see examples (10), (11) and (12), as Figure 2 shows.

Figure 2. Distribution of Negative Markers for the Past Tense

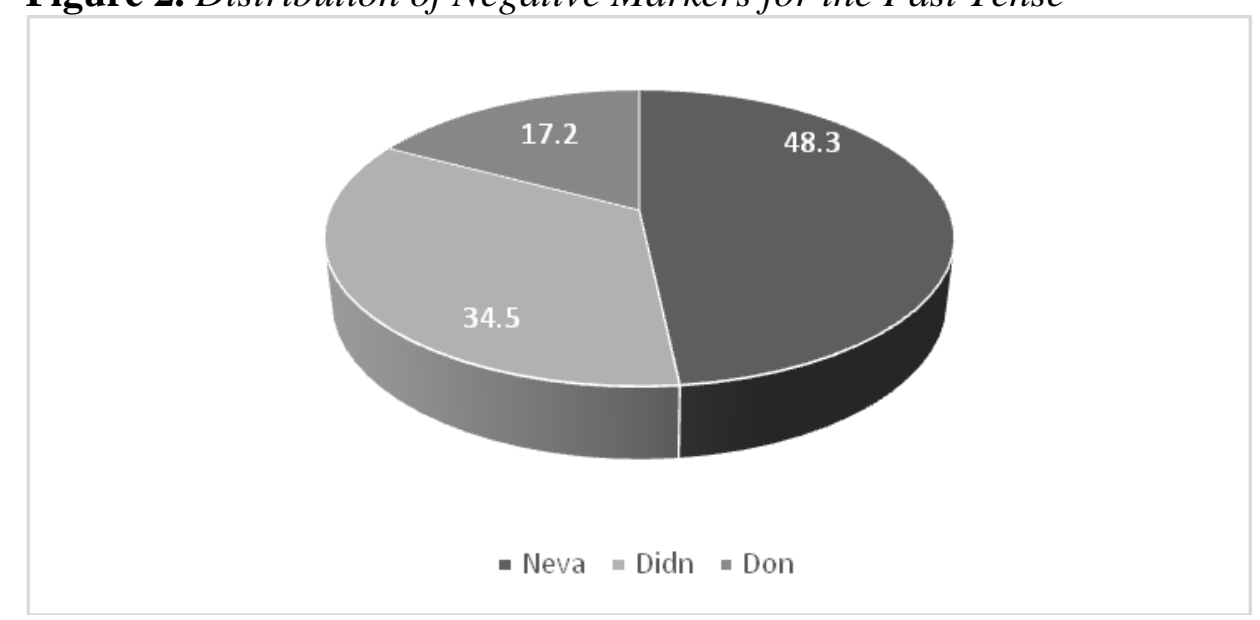

It can be argued that neva is used as an adverbial of time, rather than a negative polarity item, as in example (13), however examples (10) or (14) show neva used unambiguously as a negative marker, frequently used in other Caribbean creoles, as well as a preverbal clausal negator in English, as reported by Lucas and David (2012) and recently by Palacios-Martínez (2018).

(13) Wel rili wi neva hongri ("Well we have never been hungry")

(14) Shi neva nou nonbadi ("She didn't know anybody") 


\section{Conclusion}

This study presents a preliminary description of Criollo Sanandresano, an English-based creole spoken in the Colombian archipelago of San Andrés, Providencia and Santa Catalina. The analysis shows that SAC shares features with other Caribbean Creoles, especially in what refers to the pronominal system, the pluralization of nouns, and the system of clausal negation. Additionally, we have observed features which seem to be specific to SAC, or at least to the sample of data we have analyzed. Despite these limitations, our results allow us to confirm relevant tendencies which reinforce previous research and, most importantly, to discover tendencies of use in the case of coexisting variants:

1. The pronominal system shows variation in terms of number, case, gender and animacy, although very frequently we come across syncretism, especially with the variable case, as described in the analysis. Another factor which seems to condition the alternative form of pronominal forms is the horror aequi principle to avoid formally (near-) identical adjacent elements.

2. Pluralization of nouns is frequently marked by adding the inflection $-s /-$ $z$, but it also coexists with uninflected nouns. As shown by the analysis, uninflected nouns are selected to express plural when there are other contextual features expressing this information. Uninflected nouns are therefore selected to avoid redundancy and foster isomorphism. Additionally, the analysis has revealed the use of the analytical plural marker dem to pluralize nouns, which would add another variant to the paradigm of pluralization of nouns in SAC.

3. Preverbal negators are the default option to mark clausal negation. The negators no and neva are the most frequently used negative polarity items in SAC, together with didn and don. The analysis shows that the distribution is conditioned by tense, since no is confined to the present tense, and neva, didn and don to the preterite.

\section{References}

Abouchaar A, Hooker YY, Robinson B (2002) Estudio lingüístico para la implementación del programa de educación bilingüe en el municipio de Providencia y Santa Catalina (Linguistic study for the implementation of the bilingual education program in the municipality of Providencia and Santa Catalina). Cuadernos del Caribe 3: 66-101.

Andrade Arbeláez J (2012) Estudio sociolingüístico de San Andrés, isla: un aporte a la cultura sandresana (Sociolinguistic study of San Andrés, island: a contribution to the Sandresana culture). Cuadernos del Caribe 8: 42-55.

Bickerton D (1981) Roots of Language. Ann Arbor: Karuma Publishers.

Bickerton D (1988) Creole languages and the bioprogram. In: FJ Newmeyer (Eds.), Linguistics: The Cambridge Survey. Volume 2: Linguistic Theory: Extensions and Implications. Cambridge: Cambridge University Press, pp. 268-284. 
Bolton K (2006) World Englishes Today. In: Kachru BB, Kachru Y, Nelson CL (Eds.), The Handbook of World Englishes. Oxford: Blackwell, pp. 240-269.

Bowie P, Dittman M (2007) El proyecto piloto trilingüe de la Universidad Cristiana de San Andrés en las escuelas Emanuel Bautista y Bautista Central en la isla de San Andrés (The trilingual pilot project of the Universidad Cristiana de San Andrés in the Emanuel Bautista and Bautista Central schools on the island of San Andrés). In: de Truscott de Mejía AM, Colmenares S (Eds.), Bialfabetismo: lectura y escritura en dos lenguas de Colombia (Bialfabetismo: reading and writing in two languages of Colombia). Cali: Universidad del Valle, pp. 67-87.

Chambers JK (2004) Dynamic typology and vernacular universals. In: Kortmann B (Eds.), Dialectology Meets Typology: Dialect Grammar from a Cross-linguistic Perspective. Berlin \& New York: De Gruyter, pp. 127-145.

Chaudenson R (1992) Des îles, des hommes, des langue (Islands, men, languages). Paris: L'Harmattan.

DeCamp D (1971) The study of pidgin and creole languages. In: Hymes D (Eds.), Pidginization and Creolization of Languages. Cambridge: Cambridge University Press, pp. 13-42.

DeCamp D (1977) The development of pidgin and creoles studies. In: Valdman A (Eds.), Pidgin and Creole Linguistics. Bloomington: Indiana University Press, pp. 3-20.

Deuber D (2014) English in the Caribbean. Variation, Style and Standards in Jamaica and Trinidad. Cambridge: Cambridge University Press.

Dittman M (1992) El Criollo sanadresano: lengua y Cultura (The Sansandresan Criollo: language and culture). Universidad del Valle.

Dryer M (1988) Universal of negative position. In: Hammond M, Moravcsik E, Wirth J (Eds.), Studies in Syntactic Typology. Amsterdam: John Benjamins, pp. 93-124.

Givón T (1984) A Functional-Typological Introduction. Volume I. Amsterdam: John Benjamins.

Guerrero CH (2008) Bilingual Colombia: What does it mean to be bilingual within the framework of the National Plan of Bilingualism? PROFILE 10: 27-45.

Hancock I (1986) The domestic hypothesis, diffusion and componentiality: an account of Atlantic Anglophone creole origins. In: Muysken P, Smith N (Eds.), Substrata versus Universals in Creole Genesis. Papers from the Amsterdam Creole Workshop, April 1985. Amsterdam: John Benjamins, pp. 71-102.

Holm JA (1988) Pidgins and Creoles. Cambridge: Cambridge University Press.

Labov W (1972) Language in the Inner City: Studies in the Black English Vernacular. Philadelphia: University of Pennsylvania Press.

Le Page RB (1977) Processes of pidginization and creolization. In: Valdman A (Eds.), Pidgin and Creole Linguistics. Bloomington: Indiana University Press, pp. 222-259.

Le Page RB, Tabouret-Keller A (1985) Acts of Identity: Creole-based Approaches to Language and Identity. Cambridge: Cambridge University Press.

Lefebvre C (1993) The role of relexification and syntactic reanalysis in Haitian Creole: methodological aspects of a research program. In: Mufwene S (Eds.), Africanisms in Afro-American language varieties. Ahens, Georgia: University of Georgia Press, pp. 254-279.

Lefebvre C (1998) Creole Genesis and the Acquisition of Grammar: the Case of Haitian Creole. Cambridge: Cambridge University Press.

Leufkens S (2015) Transparency in Language. A Typological Study. PhD Dissertation. Utrecht: LOT. Available at http://dare.uva.nl/document/2/ 155071. 
Lucas C, Villis D (2012) Never again: the multiple grammaticalization of never as a marker of negation in English. English Language and Linguistics 16(3): 459485.

McWhorter J (2005) Defining Creole. Oxford: Oxford University Press.

Morren RE (2001) Creole-based Trilingual Education in the Caribbean Archipelago of San Andres, Providence and Santa Catalina. Journal of Multilingual and Multicultural Development 22(3): 227-241.

Moya-Chaves DS (2010) Situación sociolingüística de la lengua creole de San Andrés: el caso de San Luis (Sociolinguistic situation of the Creole language of San Andrés: the case of San Luis). BA Thesis, Universidad Nacional de Colombia.

Mülhäusler P (1986) Pidgin and Creole Linguistics. Oxford: Basil Blackwell.

Muysken P, Smiths N (1995) Pidgins and Creoles: An Introduction. Amsterdam: John Benjamins.

O’Flynn de Chaves C (2002) Una descripción lingüística del criollo de San Andrés (A linguistic description of the San Andrés Creole). Cuadernos del Caribe 3: 19-22.

Palacios-Martínez I (2018) You said Amy, didn't you? No, I never. A study of never as a marker of negation in the language of London English adults and teenagers. Paper presented at ICNICE18, Santiago de Compostela.

Patiño-Roselli C (2002) Sobre las dos lenguas criollas de Colombia (On the two creole languages of Colombia). Cuadernos del Caribe 3: 13-18.

Rohdenburg G (1996) Cognitive complexity and increased grammatical explicitness in English. Cognitive Linguistics 7: 149-182.

Sanmiguel R (2007) El bilingüismo en el Archipiélago de San Andrés, Providencia y Santa Catalina (Bilingualism in the Archipelago of San Andrés, Providencia and Santa Catalina). Revista Internacional Magisterio 25: 28-31.

Singh I (2000) Pidgins and Creoles: An Introduction. London: Arnold.

Singler JV (1996) Theories of creole genesis, sociohistorical considerations, and the evaluation of evidence: the case of Haitian Creole and the Relexification Hypothesis. Journal of Pidgins and Creole Languages 11: 185-230.

Stewart WA (1962) Creole languages in the Caribbean. In: Rice FA (Eds.), Study of the Role of Second Languages in Asia, Africa and Latin America. Washingtong: Center for Applied Linguistics, 34-53.

Thomason S (2001) Language Contact. Edinburgh: Edinburgh University Press.

Winford D (1993) Predication in Caribbean English Creoles. Amsterdam: John Benjamins. 
